\title{
Abscisic Acid Promotes Susceptibility to the Rice Leaf Blight Pathogen Xanthomonas oryzae pv oryzae by Suppressing Salicylic Acid-Mediated Defenses
}

\author{
Jing $\mathrm{Xu}^{1}$, Kris Audenaert ${ }^{1,2}$, Monica Hofte ${ }^{19}$, David De Vleesschauwer ${ }^{1 * 9}$ \\ 1 Laboratory of Phytopathology, Ghent University, Ghent, Belgium, 2 Faculty of Applied Bioscience Engineering, Ghent University College, Ghent, Belgium
}

\begin{abstract}
The plant hormone abscisic acid ( $A B A)$ is involved in a wide variety of plant processes, including the initiation of stressadaptive responses to various environmental cues. Recently, $A B A$ also emerged as a central factor in the regulation and integration of plant immune responses, although little is known about the underlying mechanisms. Aiming to advance our understanding of $A B A$-modulated disease resistance, we have analyzed the impact, dynamics and interrelationship of $A B A$ and the classic defense hormone salicylic acid (SA) during progression of rice infection by the leaf blight pathogen Xanthomonas oryzae pv. oryzae (Xoo). Consistent with ABA negatively regulating resistance to Xoo, we found that exogenously administered $A B A$ renders rice hypersusceptible to infection, whereas chemical and genetic disruption of $A B A$ biosynthesis and signaling, respectively, led to enhanced Xoo resistance. In addition, we found successful Xoo infection to be associated with extensive reprogramming of $A B A$ biosynthesis and response genes, suggesting that $A B A$ functions as a virulence factor for Xoo. Interestingly, several lines of evidence indicate that this immune-suppressive effect of $A B A$ is due at least in part to suppression of SA-mediated defenses that normally serve to limit pathogen growth. Resistance induced by the ABA biosynthesis inhibitor fluridone, however, appears to operate in a SA-independent manner and is likely due to induction of non-specific physiological stress. Collectively, our findings favor a scenario whereby virulent Xoo hijacks the rice $A B A$ machinery to cause disease and highlight the importance of ABA and its crosstalk with SA in shaping the outcome of rice-Xoo interactions.
\end{abstract}

Citation: Xu J, Audenaert K, Hofte M, De Vleesschauwer D (2013) Abscisic Acid Promotes Susceptibility to the Rice Leaf Blight Pathogen Xanthomonas oryzae pv oryzae by Suppressing Salicylic Acid-Mediated Defenses. PLoS ONE 8(6): e67413. doi:10.1371/journal.pone.0067413

Editor: Ching-Hong Yang, University of Wisconsin-Milwaukee, United States of America

Received February 24, 2013; Accepted May 17, 2013; Published June 27, 2013

Copyright: (C) $2013 \mathrm{Xu}$ et al. This is an open-access article distributed under the terms of the Creative Commons Attribution License, which permits unrestricted use, distribution, and reproduction in any medium, provided the original author and source are credited.

Funding: Financial support was provided by grants from the Special Research Fund of Ghent University BOF/GOA (http://www.ugent.be/en/research/funding) and by grants from the China Scholarship Council to J.X. and the Research Foundation Flanders (FWO-Vlaanderen, www.fwo.be) to D.D.V. The funders had no role in study design, data collection and analysis, decision to publish, or preparation of the manuscript.

Competing Interests: The authors have declared that no competing interests exist.

* E-mail: david.devleesschauwer@ugent.be

9 These authors contributed equally to this work.

\section{Introduction}

As sessile organisms, plants are continuously threatened by a suite of biotic and abiotic stress factors. Many of the defense mechanisms employed to counteract these stresses are controlled by an array of signal transduction pathways within which plant hormones function as key signaling molecules. Salicylic acid (SA), jasmonic acid (JA) and ethylene (ET) are the classic immunity hormones, while the importance of other small-molecule hormones including auxin, brassinosteroids (BR), gibberellic acid (GA), cytokinins ( $\mathrm{CK}$ ) and abscisic acid (ABA) is now gaining momentum [1-5]. Upon infection, plants produce a highly specific blend of hormonal alarm signals, resulting in the activation of disparate sets of attacker-specific immune responses [6]. SA, for instance, is commonly associated with defense against biotrophic pathogens, whereas necrotrophic pathogens are generally believed to be deterred by JA/ET-driven defenses [3].

Yet, rather than driving independent, linear routes of signal processing, hormones function within complex regulatory networks that connect the different pathways, enabling each to assist or antagonize the others. This interplay or so-called 'crosstalk' between individual hormones is thought to confer flexibility to the immune response, allowing the plant to adjust its inducible defense arsenal to the type of attacker encountered [7]. Exciting new developments, however, indicate that crosstalk may also allow successful pathogens to manipulate the plant's defense signaling network for their own benefit by shutting down effective defenses [8]. A classic example reflecting this situation is the production by some Pseudomonas syringae strains of a phytotoxin called coronatine that structurally resembles JA derivatives, including JA-isoleucine [9]. Coronatine is actively secreted in the host and hyperactivates JA signaling, resulting in suppression of effectual SA-mediated defenses and increased disease susceptibility [10,11].

Contrary to the relative wealth of information with respect to SA, JA and ET serving as defense regulators, the role of abscisic acid (ABA) in plant innate immunity is still poorly understood. Most comprehensively studied for its role in plant responses to environmental stresses, ABA has only recently emerged as a pivotal determinant in the outcome of plant-pathogen interactions $[1,12,13]$. In some interactions, ABA positively influences disease outcomes. For instance, ABA primes for callose deposition and thereby enhances basal defense against the powdery mildew fungus Blumeria graminis and the necrotrophic fungus Alternaria 
brassicicola, and also activates JA-mediated resistance against the oomycete Pythium irregulare [14,15]. In addition, ABA is required for stomatal closure, which as part of the SA-mediated preinvasion immune response, is a major barrier against bacterial invasion [16]. In most cases, however, ABA acts as a negative regulator of disease resistance with inhibition of $\mathrm{ABA}$ biosynthesis and/or signal transduction commonly resulting in enhanced disease resistance to a wide variety of bacterial, fungal and oomycete pathogens exhibiting distinct parasitic habits [17-25]. The importance of ABA in plant immunity is underscored by the ability of pathogens to either produce ABA themselves and/or to modify ABA biosynthesis and signaling in planta. In Arabidopsis, for instance, it was shown that $P$. syringae hijacks the ABA biosynthetic and response machinery to cause disease, indicating that $\mathrm{ABA}$ is a susceptibility factor for this bacterium [17]. Similarly, Jiang et al. (2010) reported transiently elevated ABA titers in rice plants attacked by the blast fungus Magnaporthe oryzae [26]. Current concepts suggest that this infection-induced ABA enables pathogens to tap into the plant's defense signaling circuitry and interfere with host immunity. In support of this notion, there is ample evidence demonstrating the ability of ABA to interfere either directly or indirectly with the SA-JA-ET backbone of the plant defense circuitry $[1,3,27,28]$. Additionally, ABA has been proposed to counteract GA-controlled defenses by promoting the stability of DELLA proteins that inhibit GA signaling [29], while exciting new molecular insights connect $\mathrm{ABA}$ also to $\mathrm{CK}$-mediated stress responses [30-33].

Rice is one of the most important staple food crops worldwide, providing the bulk of the daily caloric intake for no less than 3 billion people living in tropical and subtropical Asia. However, despite its emergence as a pivotal model for studying innate immunity in monocotyledonous plants [34], studies addressing the role of plant hormones, and especially $\mathrm{ABA}$, in the rice defensive machinery are scarce. In previous work, we have shown that ABA enhances basal resistance against the rice brown spot pathogen Cochliobolus miyabeanus by preventing the fungus from hijacking the ET pathway [35]. Interestingly, these ABA and ET-provoked effects are reverse of those against the blast fungus $M$. oryzae. In this pathosystem, ABA is thought to condition susceptibility via suppression of effectual ET- and SA-mediated defenses [26,36]. In contrast, molecular information regarding the role of $\mathrm{ABA}$ in bacterial leaf blight (BLB) disease is still elusive. BLB, caused by the gram-negative bacterium Xanthomonas oryzae pv. oryzae $(X o 0)$, is one of the most widespread and destructive rice diseases, causing annual yield losses up to $60 \%$ [37]. Aiming to further decipher the molecular underpinnings of ABA-modulated rice immunity, we sought to determine the impact, dynamics and inter-relationship of $\mathrm{ABA}$ with other hormones during progression of $X_{0 o}$ infection. Through genetic, physiological and pathological analyses, we show that ABA suppresses basal immunity of rice against virulent $X_{00}$ and likely functions as a virulence factor for the bacterium. Moreover, we demonstrate that ABA induces susceptibility of rice to $X o o$ by attenuating effectual SA defenses and provide evidence that this ABA-SA antagonism occurs downstream of SA biosynthesis, but upstream or at the level of the master defense regulators OsNPR1 and OsWRKT45.

\section{Materials and Methods}

\section{Plant Materials and Growth Conditions}

Seeds of the OsWRKR13-OX [38], the OsNPR1-OX and the OsNPR1 RNAi transgenics [39] and their respective wild-type lines Mudanjiang and Taipei were kindly provided by Dr. Wang (Huazhong Agricultural University, China) and Dr. He (Shanghai
Institute for Biological Sciences, China), respectively. Rice $N$ NahG [40] and OsMPK5 RNAi [41] seeds, and their parental line, japonica cultivar Nipponbare, were kind gifts from Dr. Yinong Yang (Pennsylvania State University, USA). Indica lines IRBB3 and IRBB13 were obtained from the International Rice Research Institute (courtesy of Casiana Vera-Cruz).

Unless stated otherwise, rice plants were grown in a hydroponic gnotobiotic system. Briefly, rice seeds were surface sterilized by agitation in $2 \%$ sodium hypochlorite for $20 \mathrm{~min}$, rinsed three times with sterile demineralized water, and germinated for 5 days at $28^{\circ} \mathrm{C}$ on wet filter paper. Germinated seedlings were first sown in sterilized vermiculite supplemented with half-strength Hoagland solution. Two weeks later, the plants (3-leaf stage) were transferred to plastic containers containing modified Hoagland solution and grown for another three weeks under growth chamber conditions $\left(28^{\circ} \mathrm{C}\right.$, relative humidity: $60 \%, 12 / 12$ light regimen). For seed multiplication, plants were propagated in the greenhouse $\left(30 \pm 4^{\circ} \mathrm{C}\right.$ and $16 \mathrm{~h}$ photoperiod) and fertilized with $0.5 \%$ ammonium sulphate every two weeks until flowering.

\section{Pathogen Culture and Inoculation Assays}

Xanthomonas oryzae pv. oryzae strain PXO99 (Philippine race 6) [42] was routinely grown on Sucrose Peptone Agar (SPA) medium at $28^{\circ} \mathrm{C}$. For inoculation experiments, single colonies were transferred to liquid SP medium and grown for $48 \mathrm{~h}$ at $28^{\circ} \mathrm{C}$. Plants were inoculated when 6 weeks olds by clipping the fifth and sixth stage leaves with scissors dipped in a solution of $X_{0 o}$ cells in water $\left(1 \times 10^{9} \mathrm{CFU} \cdot \mathrm{mL}^{-1}\right)$. Inoculated plants were kept in a dew chamber $\left(\geq 92 \%\right.$ relative humidity; $\left.28 \pm 2{ }^{\circ} \mathrm{C}\right)$ for $24 \mathrm{~h}$ and thereafter transferred to greenhouse conditions for disease development. Fourteen days after inoculation, disease severity was assessed by measuring the length of the water-soaked lesions. For bacterial growth analysis, inoculated leaves from three plants were pooled, ground up thoroughly using mortar and pestle and resuspended in 5 to $10 \mathrm{ml}$ water. The leaf suspensions were diluted accordingly and plated on SPA. Plates were incubated at $28^{\circ} \mathrm{C}$ and colonies were counted within 2-3 days.

\section{Chemical Treatments}

Stock solutions of SA (Sigma, Bornem, Belgium) were prepared directly in water, whereas fluridone (Fluka, Bornem, Belgium) and ABA (Duchefa, Schaarbeek, Belgium) were first dissolved in a few drops of methanol and ethanol, respectively. Equivalent volumes of both solvents were added to separate control treatments to ensure they did not interfere with the experiments. Fluridone was applied 6 days before $X_{0 o}$ inoculation by adding the compound to the modified Hoagland solution at a concentration of $0.4 \mu \mathrm{M}$. $\mathrm{ABA}$ and $\mathrm{SA}$, on the other hand, were diluted in $0.02 \%(\mathrm{v} / \mathrm{v})$ Tween 20 and applied as a foliar spray $72 \mathrm{~h}$ before inoculation. Control plants were sprayed evenly with $0.02 \%$ (v/v) Tween 20 only. For crosstalk experiments, fresh leaves from 6 -week old rice seedlings were detached, cut into $3 \mathrm{~cm}$ pieces and subsequently incubated in the indicated hormone solutions for $8 \mathrm{~h}$ at $28^{\circ} \mathrm{C}$. Leaf pieces from 13 plants were pooled and distributed randomly across the different treatments.

\section{RNA Extraction and Quantitative RT-PCR}

Total leaf RNA was extracted using TRIZOL reagent (Invitrogen) and subsequently treated with Turbo DNase (Ambion) to remove genomic DNA contamination. First-strand cDNA was synthesized from $2 \mu \mathrm{g}$ of total RNA using Multiscribe reverse transcriptase (Applied Biosystems) and random primers following the manufacturer's instructions. Quantitative PCR amplifications were conducted in optical 96-well plates with the Mx3005P real-time 
PCR detection system (Stratagene), using Sybr Green master mix (Fermentas) to monitor dsDNA synthesis. The expression of each gene was assayed in duplicate in a total volume of $25 \mu \mathrm{L}$ including a passive reference dye (ROX) according to the manufacturer's instructions (Fermentas). The thermal profile used consisted of an initial denaturation step at $95^{\circ} \mathrm{C}$ for $10 \mathrm{~min}$, followed by 40 cycles of $95^{\circ} \mathrm{C}$ for $15 \mathrm{~s}, 59^{\circ} \mathrm{C}$ for $30 \mathrm{~s}$, and $72^{\circ} \mathrm{C}$ for $30 \mathrm{~s}$. To verify amplification of one specific target cDNA, a melting-curve analysis was included according to the thermal profile suggested by the manufacturer (Stratagene). The amount of plant RNA in each sample was normalized using $e E F 1 \alpha$ (Eukaryotic elongation factor 1alpha) as internal control [43]. Nucleotide sequences of all primers used are listed in Table S1. Group-wise comparison and statistical analysis of relative expression results was performed using Relative Expression Software Tool (RESTC) [44].

\section{Results}

\section{ABA Negatively Regulates Resistance to Xoo}

In a first attempt to unravel the role of $\mathrm{ABA}$ in the rice- $X o 0$ pathosystem, we examined the effect of exogenous hormone application on subsequent pathogen inoculation. To this end, leaves of 6-week-old indica cultivars IRBB3 and IRBB13 were sprayed until runoff with a $100 \mu \mathrm{M}$ ABA solution and, three days later, inoculated with Xoo strain PXO99 using the leaf-clipping method [45]. PXO99 is virulent to IRBB3, but avirulent to IRBB13 which harbors the recessive $R$ gene xa13 [46]. In all bioassays, disease development was routinely monitored at $14 \mathrm{dpi}$ by recording the length of the water-soaked lesions characteristic of leaf blight disease. As shown in Figures $1 \mathrm{~A}$ and $1 \mathrm{C}$, exogenous ABA application significantly lowered basal disease resistance in the susceptible IRBB3 background, with average lesions of $18 \mathrm{~cm}$ on ABA-treated plants compared to control, non-treated plants, which displayed average lesion lengths of $12 \mathrm{~cm}$. In contrast, resistant IRBB13 seedlings inoculated with PXO99 displayed only marginal symptom development (lesions shorter than $1 \mathrm{~cm}$ ) and ABA pretreatment appeared to have little or no effect in this background.

To further characterize the effect of ABA on Xoo immunity, we next assessed the impact of in planta ABA levels. Due to the lack of well-characterized ABA-deficient mutants in rice, a pharmacological approach was followed whereby hydroponically grown IRBB3 and IRBB13 plants were supplied for 6 days with the ABA biosynthesis inhibitor fluridone [47], and subsequently inoculated with PXO99. Corroborating our results with exogenous ABA, fluridone application substantially reduced disease severity in susceptible IRBB3, but failed to exert an additive effect on the already high levels of Xoo resistance in IRBB13 (Figure 1A). Importantly, fluridone had no significant effect on in vitro growth of PXO99 (data not shown), demonstrating the involvement of plant-mediated responses.

Bacterial growth analyses correlated well with lesion length developments (Figure 1B). At 16 dpi, PXO99 titers reached approximately $2 \times 10^{10} \mathrm{cfu} /$ leaf in ABA-pretreated IRBB3, a greater than 100-fold increase compared to non-treated control IRBB3. In fluridone-treated IRBB3, however, PXO99 grew 10fold less than in the controls with populations leveling off to fewer than $2 \times 10^{7} \mathrm{cfu} /$ leaf. In contrast, no significant differences between treatments could be observed in resistant IRBB13 where PXO99 populations reached approximately $8 \times 10^{6} \mathrm{cfu} /$ leaf within 16 dpi. Together with the results from the lesion length measurements, these data strongly suggest that ABA suppresses basal immunity to $X_{0 o}$ and, hence, acts as a negative regulator of BLB resistance.
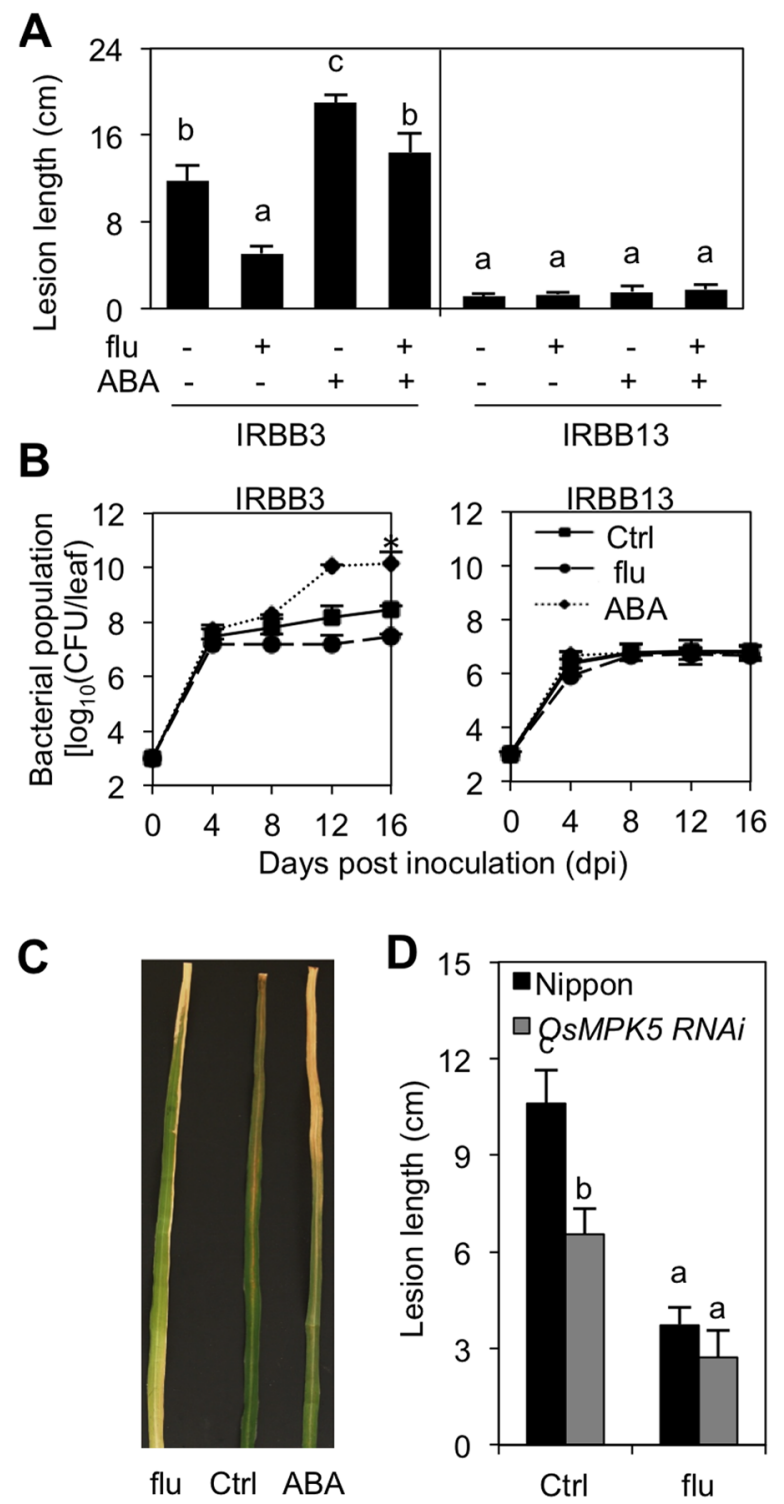

Figure 1. Effect of exogenous and endogenous abscisic acid (ABA) on bacterial leaf blight (BLB) development in rice. ( $A$ ). Susceptible IRBB3 and resistant IRBB13 plants were pretreated with ABA $(100 \mu \mathrm{M})$ and/or the $A B A$ inhibitor fluridone (flu; $0.4 \mu \mathrm{M})$ for 3 and 6 days, respectively. Fifth and sixth stage leaves were inoculated with Xanthomonas oryzae pv. oryzae (Xoo) strain PXO99 using the standard leaf-clipping method. Fourteen days post inoculation (dpi), disease was evaluated by measuring the length of the water-soaked BLB lesions. Data are means \pm SE of at least 10 plants. Different letters indicate statistically significant differences (Mann-Whitney: $n \geq 20 ; \alpha=0.05$ ). (B). Effect of ABA $(100 \mu \mathrm{M}$ and fluridone $(0.4 \mu \mathrm{M})$ on PXO99 titers in susceptible IRBB3 and resistant IRBB13. Data are means \pm SE of three biological replicates. Asterisks indicate statistically significant differences compared to control treatments (LSD; $n=3 ; \alpha=0.05$ ). (C). Symptom development on Ctrl, ABA or fluridone-pretreated IRBB3 leaves at $14 \mathrm{dpi}$. (D). Effect of fluridone $(0.4 \mu \mathrm{M})$ on BLB development in OsMPK5 RNAi and WT Nipponbare plants. Data are means \pm SE of at least 10 plants. Different letters indicate statistically significant differences (Mann-Whitney: $\mathrm{n} \geq 20 ; \alpha=0.05$ ). All experiments were repeated at least twice with similar results.

doi:10.1371/journal.pone.0067413.g001

To substantiate this hypothesis, we quantified the level of basal and fluridone-inducible $X_{0 o}$ resistance in plants silenced for the MAP kinase gene OsMPK5. One of the better studied MAP kinases 
in rice, $O s M P K 5$ has been shown to function as a positive regulator of ABA signaling in rice [41]. Accordingly, OsMPK5 RNAi plants are partially $\mathrm{ABA}$-insensitive and display reduced expression of ABA-responsive genes [36]. As shown in Figure 1D and consistent with previous results [34], non-treated OsMPK5 RNAi plants were significantly less susceptible to PXO99 than similarly treated wildtype plants, while fluridone application was equally effective in both genotypes, further confirming the negative impact of ABA on basal $X o o$ resistance.

\section{Temporal Dynamics of ABA Biosynthesis and Signaling in Response to $X_{0 o}$ Inoculation}

To gain more insight into the mechanism(s) of ABA-induced $X o 0$ susceptibility, we monitored the steady-state mRNA levels of several ABA biosynthetic and ABA responsive genes in control and ABA-pretreated IRBB3 leaves at various times after inoculation with PXO99. As shown in Figures 2A-B, expression of the ABA biosynthetic genes OSNCED3 and OsNCED4 remained static at early time points but increased steadily from 4 dpi and peaked at 8 dpi at approximately 10 and 150 times the levels found in noninoculated controls, respectively. Interestingly, transcription of the ABA-responsive genes OsLip 9 and OsRab16 mirrored the profiles observed for $O s \mathcal{N} C E D 3$ and $O S \mathcal{N} C E D 4$, these genes being strongly upregulated at 4 and 8 dpi. Comparing control and ABA-treated samples at $0 \mathrm{dpi}$, no major differences could be observed for both OsNCED4 and OsLip9. Expression of OsNCED3 and OsRab16, on the other hand, was significantly higher in ABA-treated samples compared to control plants. In a similar vein, ABA application strongly boosted the expression of OsNCED4 and both ABAresponsive genes following $X_{o o}$ attack, especially at $8 \mathrm{dpi}$ (Figure 2B-D).

In a set of parallel experiments, we also studied the expression profiles of OsNCED3, OsLip9 and OsRab16 in response to fluridone application. In line with abovementioned results, expression of these genes responded strongly to $X_{0 o}$ infection from 4 dpi onward (Figure 3A-C), whereas fluridone application strongly alleviated this pathogen-induced activation. Thus, ABA pretreatment boosts basal and/or pathogen-induced expression of ABA-responsive genes and enhances susceptibility to $X o o$, whereas fluridone inhibits ABA-responsive gene expression and increases resistance to $X o o$. When considered together, these data indicate that successful $X_{0 o}$ infection is associated with extensive reprogramming of ABA biosynthesis and ABA responsive genes. Moreover, in conjunction with earlier findings that $\mathrm{ABA}$ titers rise to a higher extent in compatible versus incompatible rice- $X o 0$ interactions [48], these observations raise the possibility that virulent $X o 0$ may hijack the rice $\mathrm{ABA}$ pathway to induce a state of susceptibility.

\section{ABA Negatively Regulates Xoo Resistance by Attenuating SA-mediated Defenses}

In Arabidopsis, ABA has been repeatedly shown to negatively regulate plant disease resistance by antagonizing the SA signaling pathway [12,24,28]. Similarly, Jiang et al. (2010) [26] reported that $\mathrm{ABA}$ compromises resistance of rice to fungal blast disease by suppressing effective SA-mediated defense responses. To further confirm antagonistic crosstalk between $\mathrm{ABA}$ and $\mathrm{SA}$ in rice and expand the scope of the investigation, we assessed the effect of single and combined hormone treatments on the expression of ABA and SA marker genes. For this purpose, leaf blade segments of 6 -week-old IRBB3 seedlings were incubated for $8 \mathrm{~h}$ in aqueous solutions of the respective hormones, and subsequently analyzed by quantitative RT-PCR. As shown in Figure 4A, single ABA treatment resulted in strong activation of the $\mathrm{ABA}$ marker gene
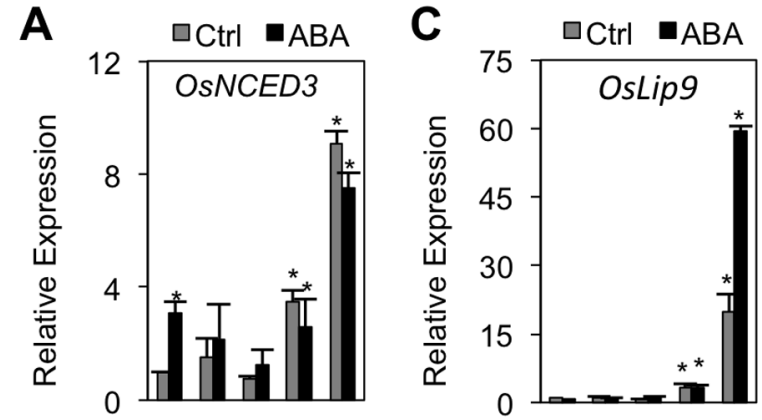

B

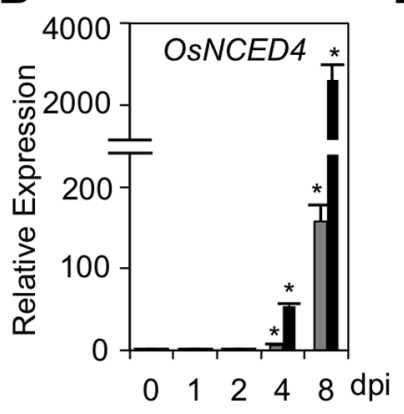

D

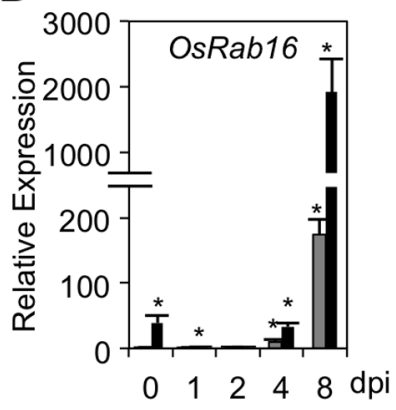

Figure 2. Dynamics of $A B A$ pathway in response to virulent Xanthomonas oryzae pv. oryzae (Xoo) infection. (A) through (D). Effect of ABA pretreatment on ABA-biosynthesis (OsNCED3, OsNCED4) and ABA-responsive genes (OsLip9 and OsRab16) in IRBB3 leaves inoculated with Xoo strain PXO99. For details on ABA pretreatment and Xoo inoculation, see legend to Figure 1. Transcript levels were normalized using eukaryotic elongation factor eEF1 $\alpha$ as an internal reference and, for each treatment, expressed relative to the normalized expression levels in mock-inoculated control plants at the appropriate time point. Data are means \pm SD of two technical and two biological replicates from a representative experiment, each biological replicate representing a pooled sample from 3 individual plants. Two sets of independent experiments were carried out with similar results. Asterisks indicate statistically significant differences per treatment compared to either control (0 dpi) or mock-treated samples (1, 2, 4 and $8 \mathrm{dpi})$. doi:10.1371/journal.pone.0067413.g002

OsLip9, while co-application of ABA with $\mathrm{SA}$ alleviated this ABAinduced OsLip9 expression, indicating negative crosstalk in the direction of SA damping ABA action. However, consistent with bidirectional SA-ABA crosstalk, we also found ABA to impact the expression of both OsNPR1 and OsWRKY 45, two master regulatory proteins that control distinct branches of the SA signaling cascade in rice [39,49]. Expression of OsWRKY45 was activated in response to $\mathrm{SA}$, whereas $\mathrm{ABA}$ suppressed both basal and SAinducible OsWRKY45 expression (Figure 4B). In contrast but consistent with previous reports on detached leaf segments [26], expression of OSNPR1 was barely responsive to exogenous SA, though it was still markedly inhibited by ABA (Figure 4G).

Having confirmed negative SA-ABA signal interactions in rice, we next sought to assess the significance of this antagonism in shaping the outcome of rice- $X_{0 o}$ interactions. To this end, leaves of 6-week-old IRBB3 were sprayed with $100 \mu \mathrm{M} \mathrm{ABA}$ and/or $500 \mu \mathrm{M} \mathrm{SA}$ and three days later, inoculated with virulent PXO99. As shown in Figure 5D, exogenous ABA treatment significantly enhanced disease susceptibility, whereas SA application rendered plants more resistant to subsequent PXO99 inoculation. Moreover, co-application with SA discounted the disease-promoting effect of single ABA treatments, suggesting that ABA may govern susceptibility to $X o 0$ at least in part by suppressing effectual SAmediated defenses. 

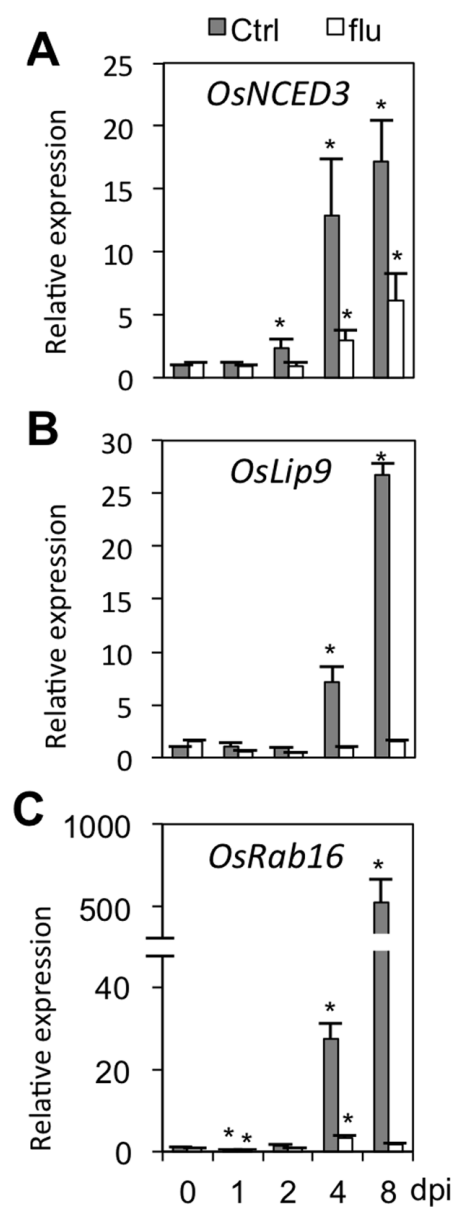

Figure 3. Cross-talk experiments demonstrating mutual antagonism between ABA and SA. IRBB3 leaf segments were incubated for $8 \mathrm{~h}$ in aequous solutions containing $50 \mu \mathrm{M}$ ABA and/or $500 \mu \mathrm{M} \mathrm{SA}$ and subsequently tested for expression of the $A B A$ responsive gene OsLip9 and SA marker genes OsNPR1 and OsWRKY45. Transcript levels were normalized using eukaryotic elongation factor $e E F 1 \alpha$ as an internal reference and for each treatment expressed relative to the normalized expression levels in non-treated control plants. Data are means \pm SD of two technical and two biological replicates from a representative experiment, each biological replicate representing a pooled sample from 13 individual plants. The experiment was repeated once with similar results. Asterisks indicate statistically significant differences compared to control, non-treated samples.

doi:10.1371/journal.pone.0067413.g003

To test this hypothesis, we monitored the temporal expression patterns of three SA regulatory genes in control and ABA-treated IRBB3 leaves following PXO99 infection. Besides OsWRKY 45 and OsNPR1, these genes included OsWRKT13, a well-characterized transcription factor gene functioning upstream of OsWRKY 45 and OsNPR1 [38,50]. Consistent with the expression profiles reported in other studies [38,51-53], expression of OsWRKY45 and OsNPR1 responded only weakly to $X_{00}$ inoculation (Figure $5 \mathrm{~A}-\mathrm{B}$ ). However, both genes were several-fold down-regulated in pathogen-inoculated leaves pretreated with ABA. Interestingly, ABA-mediated suppression of OsWRKY 45 was evident at 4 and 8 dpi only, which is in line with the upregulation of ABA biosynthesis and ABA signaling genes at these time points. In contrast, expression of OsWRKY13 was not responsive to ABA treatment at any time point (Figure 5C), suggesting that ABA antagonizes SA-mediated Xoo resistance downstream of OsWRKY13. This notion was further
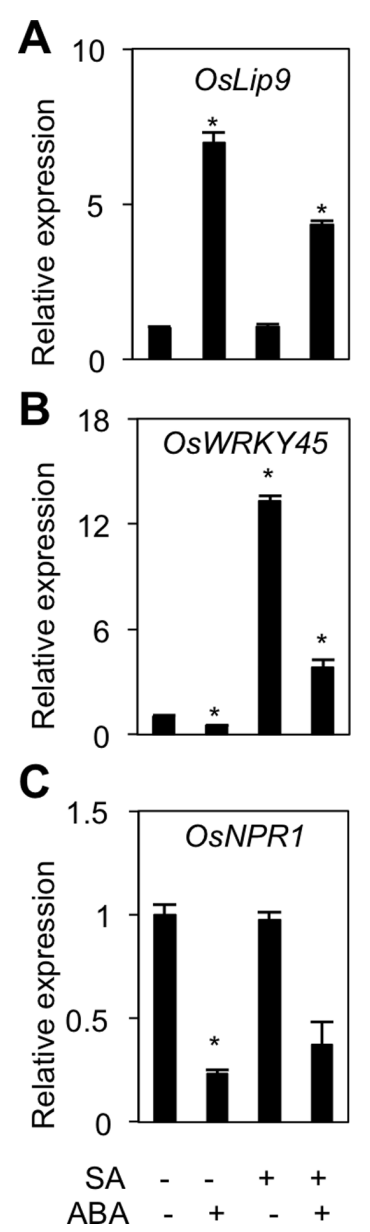

Figure 4. ABA counteracts SA-mediated defenses to Xoo. (A) through (C). Expression of SA marker genes OsWRKY45, OsNPR1 and OsWRKY13 in control (Ctrl) and ABA pretreated IRBB3 leaves inoculated with PXO99. Transcript levels were normalized using eukaryotic elongation factor eEF1 $\alpha$ as an internal reference and for each treatment expressed relative to the normalized expression levels in mockinoculated control plants at the appropriate time point. Data are means \pm SD of two technical and two biological replicates from a representative experiment, each biological replicate representing a pooled sample from 3 individual plants. Asterisks indicate statistically significant differences per treatment compared to either control $(0 \mathrm{dpi})$ or mock-treated samples (1, 2, 4 and $8 \mathrm{dpi})$. (D). Effect of single and combined pretreatment with ABA $(100 \mu \mathrm{M})$ and/or SA $(500 \mu \mathrm{M})$ on BLB development in susceptible IRBB3 plants. Lesions were measured 14 days after inoculation with PXO99. Data are means \pm SE of at least 10 plants. Different letters indicate statistically significant differences (Mann-Whitney; $n \geq 20 ; \alpha=0.05$ ) (E) and (F). Effect of exogenous ABA treatment $(100 \mu \mathrm{M})$ on BLB development in OsNPR1-OX and OsWRKY13OX lines and their respective WT Taipei and Mudanjiang. Data are means \pm SE of at least 10 plants. Different letters indicate statistically significant differences (Mann-Whitney; $n \geq 20 ; \alpha=0.05$ ). Repetition of experiments led to results similar to those shown.

doi:10.1371/journal.pone.0067413.g004

supported by the different effects of ABA pretreatment on BLB development in transgenic rice lines overexpressing OsNPR1 and OsWRKY13. Consistent with previous studies [38,39], both OsNPR1OX and OsWRKY13-OX lines exhibited increased resistance to Xoo compared to the respective wild-types (Figure 5E-F). However, while ABA application significantly promoted disease development in both WT and OsWRKY13-OX backgrounds, overexpressing OsNPR1 fully blocked ABA-inducible Xoo susceptibility. Collectively, 

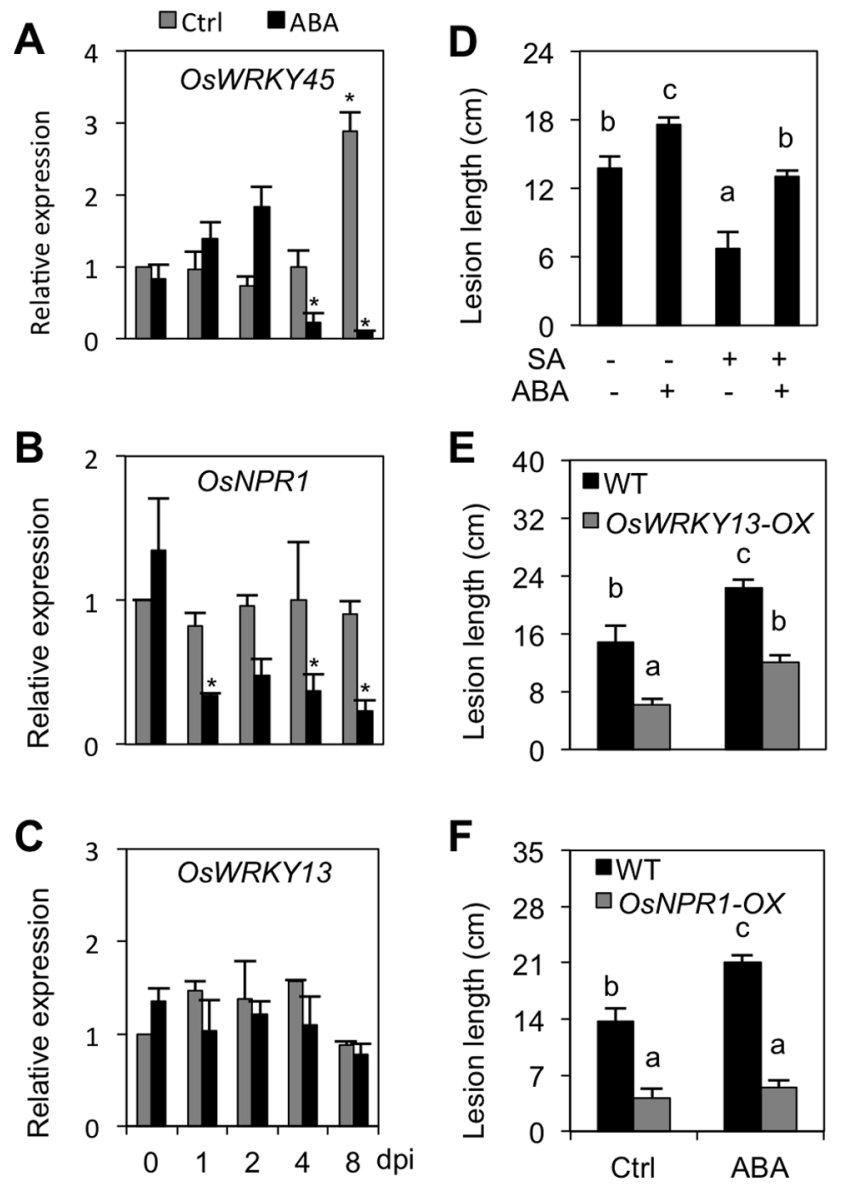

Figure 5. Fluridone suppresses pathogen-induced transcription of ABA biosynthesis and response genes. (A) through (C). Relative expression of $A B A$ biosynthesis and responsive genes, OsNCED3, OsLip9 and OsRab16, in control (Ctrl) and fluridone-pretreated $(0.4 \mu \mathrm{M})$ IRBB3 leaves inoculated with PXO99. Transcript levels were normalized using eukaryotic elongation factor eEF $1 \alpha$ as an internal reference and expressed relative to the normalized expression levels in mock-inoculated control plants at the appropriate time point. Data are means \pm SD of two technical and two biological replicates from a representative experiment, each biological replicate representing a pooled sample from 3 individual plants. Two sets of independent experiments were carried out with similar results. Asterisks indicate statistically significant differences per treatment compared to either control (0 dpi) or mock-treated samples (1, 2, 4 and $8 \mathrm{dpi})$.

doi:10.1371/journal.pone.0067413.g005

these data further confirm mutually antagonistic SA-ABA crosstalk during leaf blight infection and strengthen the hypothesis that $\mathrm{ABA}$ suppresses SA defenses downstream of OsWRKY13 but upstream of OSNPR1.

Fluridone-inducible Xoo Resistance is Independent of SA

The observation that ABA induces Xoo susceptibility, at least in part, by antagonizing the SA pathway prompted us to check whether ABA-lowering fluridone induces resistance by de-repressing SA-mediated immune responses. To address this hypothesis, we initially checked the impact of fluridone application on the expression of the SA marker genes OsWRKY45, OsNPR1 and OsWRKY13 in IRBB3 leaves infected with PXO99. Consistent with Figures 5A-C, expression of OsWRKY45, OsNPR1 and OsWRKY13 showed little changes in response to PXO99 inoculation (Figure 6A-C). However, unlike the situation in
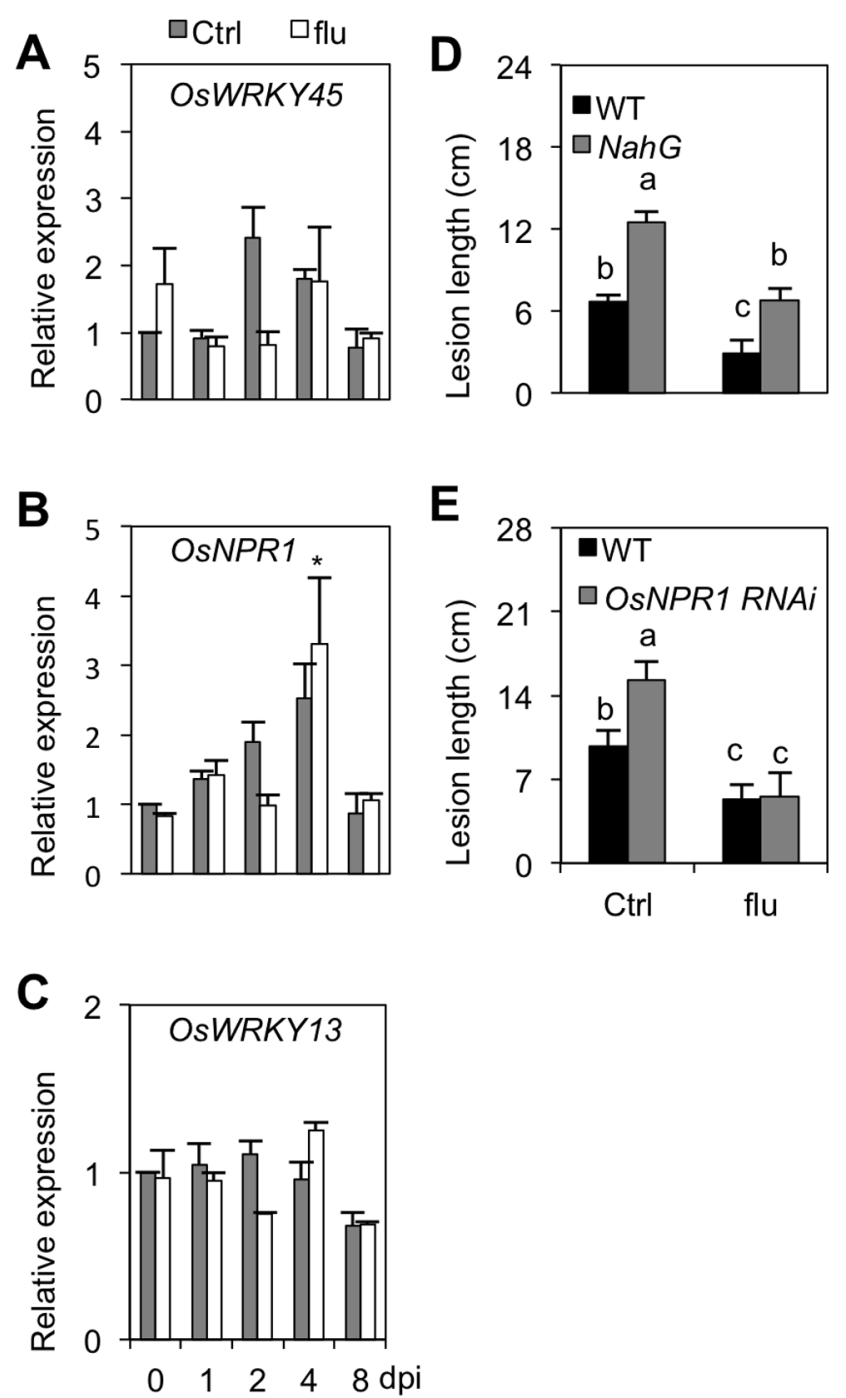

Figure 6. Fluridone induced $X o o$ resistance is independent of SA. (A) through (C). Transcript levels of the SA regulatory genes OsWRKY45, OsNPR1 and OsWRKY13 in control and fluridone-treated $(0.4 \mu \mathrm{M})$ IRBB3 leaves inoculated with PXO99. Data are means \pm SD of two technical and two biological replicates, each biological replicate representing a pooled sample from 3 individual plants. Asterisks indicate statistically significant differences per treatment compared to either control (0 dpi) or mock-treated samples (1, 2, 4 and 8 dpi). (D) and $(\mathrm{E})$. Effect of fluridone $(0.4 \mu \mathrm{M})$ on BLB development in OsNPR1 RNAi and NahG-expressing lines and their respective WT Taipei and Nipponbare. Data are means \pm SE of at least 10 plants. Different letters indicate statistically significant differences (Mann-Whitney; $n \geq 20$; $\alpha=0.05$ ). Repetition of experiments led to results similar to those shown.

doi:10.1371/journal.pone.0067413.g006

ABA-treated leaves, no major and/or consistent changes in gene expression could be noticed between control and fluridone-treated samples, suggesting that fluridone-mediated resistance is not reliant on the SA pathway.

To further probe whether fluridone operates in an SAindependent manner, we quantified the level of fluridone-inducible resistance in both SA-non accumulating $N a h G$ and OsNPR1 RNAi lines. As shown in Figure 6D, NahG plants were significantly more sensitive to pathogen attack than corresponding wild-type seedlings, demonstrating the importance of SA biosynthesis in basal resistance 
to Xoo. SA accumulation, however, did not appear to be a prerequisite for fluridone-inducible resistance, as fluridone application was equally effective in WT Nipponbare and $\mathcal{N} a h G$ plants, causing an approximate 50\% reduction in basal disease susceptibility in both genotypes. Similarly, fluridone triggered high levels of resistance in both WT Taipei and OSNPR1 RNAi plants, indicating that, unlike ABA, fluridone functions independently of OsNPR1 (Figure 6E).

\section{Discussion}

Bacterial leaf blight (BLB), caused by the gram-negative bacterium Xanthomonas oryzae pv. oryzae $(X o o)$, is one of the most devastating rice diseases owing to its widespread distribution and high pathogenic variability. However, despite the accumulated wealth of genetic and molecular resources in rice and the identification of over 30 major resistance genes for BLB [37], surprisingly little is known about the hormone signaling pathways underpinning disease and resistance in the rice-Xoo pathosystem. Previously, Ding et al. [54] showed that auxin promotes susceptibility to $X o o$ through induced expression of cell wall-loosening expansins. In contrast, SA and JA act as positive regulators of immunity against $X_{o o}[38,39,53]$, while GA and ET are reported to suppress BLB resistance through yet to be defined mechanisms $[55,56]$. In adding to this list, our results uncover $\mathrm{ABA}$ as an additional negative regulator of rice- $X_{0 o}$ interactions. Moreover, our findings highlight the importance of bidirectional ABA-SA signal interactions in determining the outcome of rice-Xoo interactions and suggest that virulent strains of $X_{0 o}$ exploit ABA to subdue the rice innate immune system and promote disease development.

\section{ABA Negatively Regulates Rice Immunity to Xoo}

Contrary to the well-characterized role of ABA in plant adaptive responses to abiotic stress [57], its contribution to plant disease resistance is relatively poorly understood, and even contentious. Whereas the majority of reports indicate that ABA suppresses pathogen defense responses [13], others have pinpointed a positive role of ABA in plant immunity $[14,35,58]$. Recent studies also found that the role of $\mathrm{ABA}$ in modulating disease resistance may depend not only on pathogen lifestyle but also on temporal and spatial conditions, indicating that complex nuanced mechanisms underlie ABA modulation of plant immunity $[1,12]$. Under our experimental conditions, exogenous ABA application significantly increased rice susceptibility to virulent $X_{o o}$ (Figure 1A), while lowering basal ABA levels by applying the ABA biosynthesis inhibitor fluridone or genetic disruption of $\mathrm{ABA}$ signaling in OsMPK5 RNAi plants led to reduced disease development (Figure 1A-B). Similar to what was previously reported for the leaf blast fungus $M$. oryzae $[26,59,60]$, ABA thus seems to act as a negative regulator of rice immunity to $X o o$.

Interestingly, both exogenous ABA treatment and fluridone application failed to alter lesion length development and bacterial growth in IRBB13 plants carrying the recessive $R$ gene $x a 13$, suggesting that ABA predominantly affects basal defense responses against $X_{o o}$. However, care should be taken when interpreting these data. Recently, Mang et al. (2012) mechanistically connected ABA to $R$ protein-mediated immunity by demonstrating that ABA deficiency in Arabidopsis promotes defense responses at high temperatures through enhancing the nuclear accumulation and activity of the resistance proteins SNC1 and RPS4 [61]. Consistent with this, exogenous ABA treatment was previously reported to compromise resistance to both virulent and avirulent blast fungus isolates, indicating that $\mathrm{ABA}$ negatively orchestrates both basal and $R$ protein-mediated resistance against $M$. oryzae [26]. Taking these facts into account, it is not inconceivable that ABA may play a role in $X_{0 o}$ resistance governed by $R$ genes other than xa13. Additional bio-assays using $X_{0 o}$ strains with different genetic backgrounds and rice lines carrying distinct types of $R$ genes will aid in deciphering the role, if any, of ABA in regulating $R$-gene mediated resistance to $X o$.

The importance of ABA in determining pathological outcomes is underscored by the efforts pathogens undertake to tap into the host ABA biosynthesis and signaling infrastructure. Recent studies have demonstrated the direct manipulation of ABA biosynthesis and signaling by bacterial type III effectors as a virulence strategy for $P$. syringae and $X$. campestris pv. campestris $[17,25,62,63]$. Moreover, in addition to modifying plant ABA biosynthesis, some phytopathogenic organisms, including the fungal pathogens $M$. oryzae, Botrytis cinerea and Rhizoctonia solani, are able to produce and secrete ABA themselves [64,65]. Since there is no compelling evidence supporting the role of ABA in the physiology of these pathogens, it is likely that pathogens have evolved ABA biosynthetic machinery to trigger ABA signaling at infection sites and dampen plant immunity [12]. Previously, Liu et al [48] demonstrated that rice plants responding to $X o 0$ attack accumulate substantial amounts of ABA from 4 dpi onwards, these levels being significantly higher in susceptible than in resistant plants. In view of these findings, the strong upregulation of ABA-biosynthesis and -responsive genes in control inoculated plants (Figure 2A-D; [48]), the disease-promoting effect of exogenously administered ABA (Figure 1A), and the positive correlation between bacterial growth and pathogen virulence on the one hand, and the amplitude of ABA-responsive gene expression on the other, strongly suggest that virulent $X_{0 o}$ may likewise co-opt the rice ABA machinery to promote bacterial growth and cause disease.

In this scenario, the identical bacterial densities observed during the first few days of inoculation in both compatible and incompatible rice- $X o 0$ interactions (Figure 1B) are suggestive of an ABA-preceding interaction phase during which host and pathogen 'battle' for dominance. Depending on the outcome of this early interaction, $X_{0 o}$ strains may or may not be capable of hijacking the rice ABA pathway at late infection to achieve their full virulent potential. Although the molecular mechanisms underlying the early steps of rice-Xoo interactions are poorly resolved, recent transcriptome analyses and combined metabolite and hormone profiling increasingly implicate a coordinated range of hormone pathways. For instance, in resistant rice responding to virulent $X_{0 o}$, both JA and ET signaling were found to be strongly activated within one hour after pathogen attack [66], whereas suppression of auxin and GA signaling seems to occur significantly later, i.e. between $12 \mathrm{hpi}$ and $3 \mathrm{dpi}[56,67]$. Together with our results, these data therefore suggest that temporally separated transient hormone changes play an important role in configuring the plant's response to Xoo attack, with both host and pathogen trying to sequentially engage distinct hormone pathways in defined temporal windows.

\section{ABA Suppresses SA-mediated Defenses}

Over the past decade, a multitude of mechanisms underpinning ABA's broad and divergent impact on plant resistance responses have been identified. Besides interfering with pathogen-induced deposition of callose and modulating production of reactive oxygen species, ABA has been repeatedly shown to influence disease outcomes by interfering with other defense hormones $[1,12]$. For instance, antagonistic or synergistic interactions between ABA and JA/ET are well known to play a pivotal role in numerous host-microbe interactions $[27,35,36,58,68]$. In 
addition, ABA has been proposed to antagonize SA-mediated signaling to regulate defense responses in tomato and Arabidopsis, where it affects both SA biosynthesis and signaling [24,62]. In a similar vein, ABA enhances susceptibility of rice to $M$. oryzae by suppressing SA-regulated defenses [26]. Interestingly, several lines of evidence suggest that negative ABA-SA crosstalk also underpins the disease-promoting effect of $\mathrm{ABA}$ during rice- $X o o$ interactions. First, lesions caused by Xoo were more severe on SA-deficient $\mathcal{N a h} G$ plants (Figure 6D), whereas topical application of SA or ectopic expression of the SA regulatory genes OsNPR1 and OsWRKY13 resulted in enhanced resistance (Figure 5D-F), tagging SA as a positive regulator of $\mathrm{BLB}$ resistance. Moreover, ABA not only antagonized SA-responsive gene expression in detached leaf assays but also down-regulated the transcription of SA regulatory genes during rice- $\mathrm{Xoo}$ interactions (Figure $4 \mathrm{~A}-\mathrm{C}$ and $5 \mathrm{~A}-\mathrm{C}$ ) and, accordingly, attenuated SA-inducible pathogen resistance (Figure 5D). Finally and consistent with reciprocal antagonism in the direction of SA damping ABA action, we found SA to alleviate ABA-triggered effects on both marker gene expression and pathogen resistance (Figure 4A-G and 5D). When considered together, these data favor a scenario whereby mutually antagonistic ABA-SA crosstalk plays a central role in shaping the outcome of rice- $X o o$ interactions.

Interestingly, our data also infer that ABA antagonizes the SA signaling pathway downstream of OsWRKY13 but upstream of OsNPR1, as overexpression of OsNPR1 but not OsWRKY13 abolished the negative impact of $\mathrm{ABA}$ on $\mathrm{BLB}$ resistance (Figure 5E-F). Potential target sites for ABA-mediated suppression of SA action include the transcription factors OsWRKY71 and OsWRKY24, both of which function as transcriptional activators of SA signaling and are differentially expressed in response to OsWRKT13 overexpression and/or ABA treatment [38,69]. Alternatively, ABA may activate negative regulators of SAresponsive gene expression that either inhibit or out-compete positive regulators. Recently, Yasuda et al. (2008) identified multiple nodes of confluence between the SA and ABA signaling pathways in Arabidopsis [24]. Exploring whether similar crosstalk mechanisms are operative in rice is a major challenge for future research.

\section{Fluridone-inducible Xoo Resistance Functions Independently of SA}

In higher plants, endogenous ABA is synthesized predominantly from zeaxanthin, which is an important intermediate in the carotenoid-biosynthesis pathway [70]. Fluridone is a herbicide that is widely used in ABA-related research because of its ability to block carotenoid synthesis, thus reducing ABA precursor pools. Based on the finding that ABA suppresses resistance to $X_{0 o}$ resistance by antagonizing SA defenses and given the strong negative effect of fluridone treatment on bacterial growth and pathogen-induced expression of $\mathrm{ABA}$ biosynthesis and response genes (Figure $1 \mathrm{~A}-\mathrm{B}$ and $3 \mathrm{~A}-\mathrm{C}$ ), we initially hypothesized fluridone to enhance resistance to $X_{0 o}$ by de-repressing the SA pathway. Surprisingly, however, we failed to observe any significant or reproducible differences in SA-responsive gene expression between control and fluridone-treated plants (Figure 6A-C). Moreover, fluridone triggered wild-type levels of resistance in both OSNPR1 RNAi and SA-deficient $N a h G$ seedlings, indicating that fluridoneinducible resistance requires neither SA biosynthesis nor SA action (Figure 6D-E). Although relatively little is known about the mechanism(s) of fluridone-mediated pathogen resistance, a few studies point to some possibilities. For example, Achuo et al. (2003) reported that micromolar concentrations of fluridone induced resistance of tomato against Botrytis cinerea without

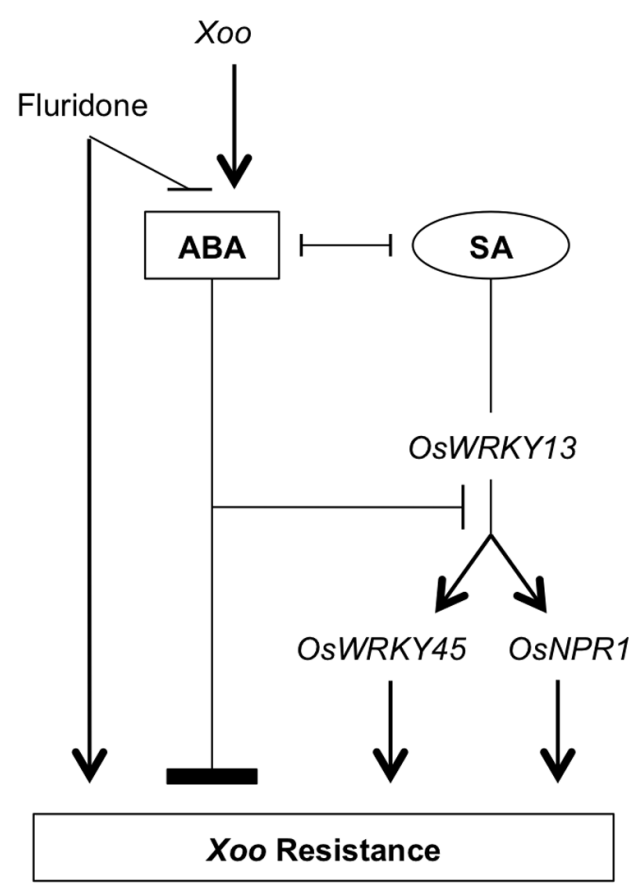

Figure 7. Model illustrating how dynamic interplay between $A B A$ and SA molds innate immunity of rice against the BLB pathogen Xoo. Sharp arrows represent stimulatory effects, blunt arrows depict antagonistic interactions. doi:10.1371/journal.pone.0067413.g007

disturbing the plant ABA pool [71]. This result could be explained by assuming that fluridone caused some sort of physiological stress, the response to which resulted in disease resistance. Supporting this hypothesis, fluridone and norflurazone, another inhibitor of ABA biosynthesis, have been shown before to provoke physiological stress in plants through photobleaching of chlorophyll, a phenomenon also observed in this study (Figure 1C) [72]. Considering the strong impact of abiotic stress factors on plant immunity and the complex interplay between biotic and abiotic stress-response signaling pathways [57,73], it is not unlikely that stress due to mild doses of photobleaching fluridone should result in disease resistance. Therefore, we propose that fluridonemediated resistance to $X o 0$ does not derive primarily from lowering ABA content and resultant activation of SA-mediated defenses, but rather is due to induction of non-specific physiological stress.

\section{Conclusions}

In conclusion, our results favor a model whereby ABA and its interaction with the SA pathway play central roles in orchestrating immunity of rice against the BLB pathogen $X_{o o}$ (Figure 7). We propose that $\mathrm{ABA}$ acts as a virulence factor for $X_{00}$ by antagonizing effectual SA-mediated defenses downstream of the master regulator OsWRKY13 but upstream of OsNPR1. In contrast, application of the ABA-lowering herbicide fluridone was found to trigger an SA-independent type of resistance. While bidirectional SA-ABA crosstalk may provide rice with a powerful potential to tailor its immune response to different types of attackers, our results suggest that virulent $X_{0 o}$ bacteria have evolved sophisticated strategies to manipulate ABA-SA interplay for their own benefit, redirecting the host immune response in favour of disease. 


\section{Supporting Information}

Table S1 Sequences of qRT-PGR primers used in this study.

(DOCX)

\section{Acknowledgments}

We would like to thank Ilse Delaeare for excellent technical assistance. We are also grateful to Dr Wang, Dr. He, Dr. Yinong Yang and Dr. Casiana Vera-Cruz for providing various rice mutant and transgenic lines.

\section{References}

1. Asselbergh B, De Vleesschauwer D, Höfte M (2008) Global switches and finetuning - ABA modulates plant pathogen defense. Mol Plant-Microbe Interact 21: 709-719.

2. Bari R, Jones J (2009) Role of plant hormones in plant defence responses. Plant Mol Biol 69: 473-488.

3. Pieterse CMJ, Van der Does D, Zamioudis C, Leon-Reyes A, Van Wees SCM (2012) Hormonal modulation of plant immunity. Annu Rev Cell Dev Biol 28: 489-521.

4. Robert-Seilaniantz A, Grant M, Jones JDG (2011) Hormone crosstalk in plant disease and defense: more than just jasmonate-salicylate antagonism. Annu Rev Phytopathol 49: 317-343.

5. De Vleesschauwer D, Van Buyten E, Satoh K, Balidion J, Mauleon R, et al. (2012) Brassinosteroids antagonize gibberellin- and salicylate-mediated root immunity in rice. Plant Physiol 158: 1833-1846.

6. De Vos M, Van Oosten VR, Van Poecke RMP, Van Pelt JA, Pozo MJ, et al. (2005) Signal signature and transcriptome changes of Arabidopsis during pathogen and insect attack. Mol Plant-Microbe Interact 18: 923-937.

7. Spoel SH, Dong XN (2008) Making sense of hormone crosstalk during plant immune responses. Cell Host Microbe 3: 348-351.

8. Pieterse CMJ, Leon-Reyes A, Van der Ent S, Van Wees SCM (2009) Networking by small-molecule hormones in plant immunity. Nat Chem Biol 5: $308-316$.

9. Staswick PE (2008) JAZing up jasmonate signaling. Trends Plant Sci 13: 66-71.

10. Brooks DM, Bender CL, Kunkel BN (2005) The Pseudomonas syringae phytotoxin coronatine promotes virulence by overcoming salicylic acid-dependent defences in Arabidopsis thaliana. Mol Plant Pathol 6: 629-639.

11. Cui J, Bahrami AK, Pringle EG, Hernandez-Guzman G, Bender CL, et al. (2005) Pseudomonas syringae manipulates systemic plant defenses against pathogens and herbivores. Proc Natl Acad Sci U S A 102: 1791-1796.

12. Cao F, Yoshioka K, Desveaux D (2011) The roles of ABA in plant-pathogen interactions. J Plant Res 124: 489-499.

13. Ton J, Flors V, Mauch-Mani B (2009) The multifaceted role of ABA in disease resistance. Trends Plant Sci 14: 310-317.

14. Ton J, Mauch-Mani B (2004) $\beta$-amino-butyric acid-induced resistance against necrotrophic pathogens is based on ABA-dependent priming for callose. Plant $\mathrm{J}$ 38: 119-130.

15. Flors V, Ton J, Van Doorn R, Jakab G, García-Agustín P, et al. (2008) Interplay between JA, SA and ABA signalling during basal and induced resistance against Pseudomonas syringae and Alternaria brassicicola. Plant J 54: 81-92.

16. He SY, Melotto M, Underwood W, Koczan J, Nomura K (2006) Plant stomata function in innate immunity against bacterial invasion. Cell 126: 969-980.

17. De Torres-Zabala M, Truman W, Bennett MH, Lafforgue G, Mansfield JW, et al. (2007) Pseudomonas syringae pv. tomato hijacks the Arabidopsis abscisic acid signalling pathway to cause disease. EMBO J 26: 1434-1443.

18. Solano R, Adie BAT, Perez-Perez J, Perez-Perez MM, Godoy M, et al. (2007) $\mathrm{ABA}$ is an essential signal for plant resistance to pathogens affecting JA biosynthesis and the activation of defenses in Arabidopsis. Plant Cell 19: 16651681 .

19. Thaler JS, Bostock RM (2004) Interactions between abscisic-acid-mediated responses and plant resistance to pathogens and insects. Ecology 85: 48-58.

20. Audenaert K, De Meyer GB, Höfte M (2002) Abscisic acid determines basal susceptibility of tomato to Botrytis cinerea and suppresses salicylic acid-dependent signaling mechanisms. Plant Physiol 128: 491-501.

21. Achuo EA, Prinsen E, Hofte M (2006) Influence of drought, salt stress and abscisic acid on the resistance of tomato to Botrytis cinerea and Oidium neolycopersici. Plant Pathol 55: 178-186.

22. Cahill DM, Mohr PG (2007) Suppression by ABA of salicylic acid and lignin accumulation and the expression of multiple genes, in Arabidopsis infected with Pseudomonas syringae pv. tomato. Func Integr Genomics 7: 181-191.

23. Asselbergh BOB, Achuo AE, Höfte M, Van Gijsegem F (2008) Abscisic acid deficiency leads to rapid activation of tomato defence responses upon infection with Erwinia chrysanthemi. Mol Plant Pathol 9: 11-24.

24. Yasuda M, Ishikawa A, Jikumaru Y, Seki M, Umezawa T, et al. (2008) Antagonistic interaction between systemic acquired resistance and the abscisic acid-mediated abiotic stress response in Arabidopsis. Plant Cell 20: 1678-1692.

25. Ho YP, Tan CM, Li MY, Lin H, Deng WL, et al. (2013) The AvrB AvrC domain of AvrXccC of Xanthomonas campestris pv. campestris is required to elicit

\section{Author Contributions}

Conceived and designed the experiments: JX MH KA DDV. Performed the experiments: JX. Analyzed the data: JX MH DDV. Contributed reagents/materials/analysis tools: KA. Wrote the paper: JX DDV. plant defense responses and manipulate ABA homeostasis. Mol Plant-Microbe Interact: DOI: 10.1094/mpmi-1006-1012-0164-r.

26. Jiang CJ, Shimono M, Sugano S, Kojima M, Yazawa K, et al. (2010) Abscisic acid interacts antagonistically with salicylic acid signaling pathway in riceMagnaporthe grisea interaction. Mol Plant-Microbe Interact 23: 791-798.

27. Anderson JP, Badruzsaufari E, Schenk PM, Manners JM, Desmond OJ, et al. (2004) Antagonistic interaction between abscisic acid and jasmonate-ethylene signaling pathways modulates defense gene expression and disease resistance in Arabidopsis. Plant Cell 16: 3460-3479.

28. Fan J, Hill L, Crooks C, Doerner P, Lamb C (2009) Abscisic acid has a key role in modulating diverse plant-pathogen interactions. Plant Physiol 150: 1750 1761.

29. Grant MR, Jones JDG (2009) Hormone (dis)harmony moulds plant health and disease. Science 324: 750-752.

30. Peleg Z, Reguera M, Tumimbang E, Walia H, Blumwald E (2011) Cytokininmediated source/sink modifications improve drought tolerance and increase grain yield in rice under water-stress. Plant Biotechnol J 9: 747-758.

31. Tran LSP, Urao T, Qin F, Maruyama K, Kakimoto T, et al. (2007) Functional analysis of AHK1/ATHK1 and cytokinin receptor histidine kinases in response to abscisic acid, drought, and salt stress in Arabidopsis. Proc Natl Acad Sci U S A 104: 20623-20628.

32. Wang Y, Li L, Ye T, Zhao S, Liu Z, et al. (2011) Cytokinin antagonizes ABA suppression to seed germination of Arabidopsis by downregulating ABI5 expression. Plant J 68: 249-261.

33. Nishiyama R, Watanabe Y, Fujita Y, Le DT, Kojima M, et al. (2011) Analysis of cytokinin mutants and regulation of cytokinin metabolic genes reveals important regulatory roles of cytokinins in drought, salt and abscisic acid responses, and abscisic acid biosynthesis. Plant Cell 23: 2169-2183.

34. Seo YS, Chern M, Bartley LE, Han M, Jung KH, et al. (2011) Towards Establishment of a Rice Stress Response Interactome. PLoS Genet 7: e1002020.

35. De Vleesschauwer D, Yang YN, Cruz CV, Höfte M (2010) Abscisic acidinduced resistance against the brown spot pathogen Cochliobolus miyabeanus in rice involves MAP kinase-mediated repression of ethylene signaling. Plant Physiol 152: 2036-2052.

36. Bailey TA, Zhou XJ, Chen JP, Yang Y (2009) Role of ethylene, abscisic acid and MAP kinase pathways in rice blast resistance. Advances in Genetics, Genomics and Control of Rice Blast Disease: Springer Netherlands. 185-190.

37. Nino-Liu DO, Ronald PC, Bogdanove AJ (2006) Xanthomonas oryzae pathovars: model pathogens of a model crop. Mol Plant Pathol 7: 303-324

38. Qiu D, Xiao J, Xie W, Liu H, Li X, et al. (2008) Rice gene network inferred from expression profiling of plants overexpressing OsWRKY13, a positive regulator of disease Resistance. Mol Plant 1: 538-551.

39. Yuan YX, Zhong SH, Li O, Zhu ZR, Lou YG, et al. (2007) Functional analysis of rice NPR1-like genes reveals that $O_{S N P R 1 / N H 1}$ is the rice orthologue conferring disease resistance with enhanced herbivore susceptibility. Plant Biotechnol J 5: 313-324.

40. Yang YN, Qi M, Mei CS (2004) Endogenous salicylic acid protects rice plants from oxidative damage caused by aging as well as biotic and abiotic stress. Plant J 40: 909-919.

41. Xiong L, Yang Y (2003) Disease resistance and abiotic stress tolerance in rice are inversely modulated by an abscisic acid-inducible mitogen-activated protein kinase. Plant Cell 15: 745-759.

42. Song WY, Chen LL, Pi LY, Gardner J, Wang B, et al. (1995) A receptor kinaselike protein encoded by the rice disease resistance gene, Xa21. Science 270: 1804-1806.

43. Jain M, Nijhawan A, Tyagi AK, Khurana JP (2006) Validation of housekeeping genes as internal control for studying gene expression in rice by quantitative realtime PCR. Biochem Biophys Res Commun 345: 646-651.

44. Pfaffl MW, Horgan GW, Dempfle L (2002) Relative expression software tool (RESTC) for group-wise comparison and statistical analysis of relative expression results in real-time PCR. Nucleic Acids Res 30: e36.

45. Kauffman HE, Reddy APK, Hsieh SPY, Merca SD (1973) An improved technique for evaluating resistance of rice varieties to Xanthomonas oryzae. Plant Dis Rep 57: 537-541.

46. Chu Z, Fu B, Yang H, Xu C, Li Z, et al. (2006) Targeting xa13, a recessive gene for bacterial blight resistance in rice. Theor App Genet 112: 455-461. 
47. Watanabe H, Takahashi K, Saigusa M (2001) Morphological and anatomical effects of abscisic acid (ABA) and fluridone (FLU) on the growth of rice mesocotyls. Plant Growth Regul 34: 273-275.

48. Liu H, Li X, Xiao J, Wang S (2012) A convenient method for simultaneous quantification of multiple phytohormones and metabolites: application in study of rice-bacterium interaction. Plant Methods 8: 2.

49. Shimono M, Sugano S, Nakayama A, Jiang CJ, Ono K, et al. (2007) Rice WRKT 45 plays a crucial role in benzothiadiazole-inducible blast resistance. Plant Cell 19: 2064-2076.

50. Qiu DY, Xiao J, Ding XH, Xiong M, Cai M, et al. (2007) OsWRKr13 mediates rice disease resistance by regulating defense-related genes in salicylate- and jasmonate-dependent signaling. Mol Plant-Microbe Interact 20: 492-499.

51. Qiu YP, Yu DQ (2009) Over-expression of the stress-induced OsWRKr45 enhances disease resistance and drought tolerance in Arabidopsis. Environ Exp Bot 65: 35-47.

52. Ryu HS, Han M, Lee SK, Cho JI, Ryoo N, et al. (2006) A comprehensive expression analysis of the $W R K r$ gene superfamily in rice plants during defense response. Plant Cell Rep 25: 836-847.

53. Tao Z, Liu HB, Qiu DY, Zhou Y, Li XH, et al. (2009) A pair of allelic WRKr genes play opposite roles in rice-bacteria interactions. Plant Physiol 151: 936948.

54. Ding X, Cao Y, Huang L, Zhao J, Xu G, et al. (2008) Activation of the indole-3acetic acid amido synthetase $G H 3-8$ suppresses expansin expression and promotes salicylate- and jasmonate-independent basal immunity in rice. Plant Cell 20: 228-240.

55. Shen XL, Liu HB, Yuan B, Li XH, Xu CG, et al. (2011) OsEDR1 negatively regulates rice bacterial resistance via activation of ethylene biosynthesis. Plant Cell Environ 34: 179-191.

56. Yang DL, Li Q, Deng YW, Lou YG, Wang MY, et al. (2008) Altered disease development in the eui Mutants and Eui overexpressors indicates that gibberellins negatively regulate rice basal disease resistance. Mol Plant 1: 528-537.

57. Fujita M, Fujita Y, Noutoshi Y, Takahashi F, Narusaka Y, et al. (2006) Crosstalk between abiotic and biotic stress responses: a current view from the points of convergence in the stress signaling networks. Curr Opin Plant Biol 9: 436-442.

58. Adie BAT, Perez-Perez J, Perez-Perez MM, Godoy M, Sanchez-Serrano JJ, et al. (2007) ABA is an essential signal for plant resistance to pathogens affecting JA biosynthesis and the activation of defenses in Arabidopsis. Plant Cell 19: 16651681 .

59. Koga H, Dohi K, Mori M (2004) Abscisic acid and low temperatures suppress the whole plant-specific resistance reaction of rice plants to the infection of Magnaporthe grisea. Physiol Mol Plant Pathol 65: 3-9.
60. Yazawa K, Jiang CJ, Kojima M, Sakakibara H, Takatsuji H (2012) Reduction of abscisic acid levels or inhibition of abscisic acid signaling in rice during the early phase of Magnaporthe oryzae infection decreases its susceptibility to the fungus. Physiol Mol Plant Pathol 78: 1-7.

61. Mang HG, Qian WQ, Zhu Y, Qian J, Kang HG, et al. (2012) Abscisic acid deficiency antagonizes high-temperature inhibition of disease resistance through enhancing nuclear accumulation of resistance proteins SNC1 and RPS4 in Arabidopsis. Plant Cell 24: 1271-1284.

62. De Torres Zabala M, Bennett MH, Truman WH, Grant MR (2009) Antagonism between salicylic and abscisic acid reflects early host-pathogen conflict and moulds plant defence responses. Plant J 59: 375-386.

63. Goel AK, Lundberg D, Torres MA, Matthews R, Akimoto Tomiyama C, et al. (2008) The Pseudomonas syringae type III effector HopAM1 enhances virulence on water-stressed plants. Mol Plant-Microbe Interact 21: 361-370.

64. Oritani T, Kiyota H (2003) Biosynthesis and metabolism of abscisic acid and related compounds. Nat Prod Rep 20: 414 425.

65. Siewers V, Kokkelink L, Smedsgaard J, Tudzynski P (2006) Identification of an abscisic acid gene cluster in the grey mold Botrytis cinerea. Appl Environ Microbiol 72: 4619-4626.

66. Grewal R, Gupta S, Das S (2012) Xanthomonas oryzae pv oryzae triggers immediate transcriptomic modulations in rice. BMC Genomics 13: 49.

67. Fu J, Liu HB, Li Y, Yu HH, Li XH, et al. (2011) Manipulating broad-spectrum disease resistance by suppressing pathogen-induced auxin accumulation in rice. Plant Physiol 155: 589-602.

68. Lackman P, Gonzalez-Guzman M, Tilleman S, Carqueijeiro I, Perez AC, et al. (2011) Jasmonate signaling involves the abscisic acid receptor PYL4 to regulate metabolic reprogramming in Arabidopsis and tobacco. Proc Natl Acad Sci U S A 108: 5891-5896.

69. Zhang ZL, Shin M, Zou XL, Huang JZ, Ho TD, et al. (2009) A negative regulator encoded by a rice WRKY gene represses both abscisic acid and gibberellins signaling in aleurone cells. Plant Mol Biol 70: 139-151.

70. Xiong LM, Zhu JK (2003) Regulation of abscisic acid biosynthesis. Plant Physiol 133: 29-36.

71. Achuo E, Audenaert K, Vanhoutte S, Höfte M (2003) Effect of abscisic acid biosynthesis inhibitor fluorochloridone on the virulence of Botrytis cinerea and Oidium neolycopersici. Commun Agricul Appl Bio Sci 68: 49-52.

72. Taylor IB, Burbidge A, Thompson AJ (2000) Control of abscisic acid synthesis. J Exp Bot 51: 1563-1574.

73. Sharma R, De Vleesschauwer D, Sharma MK, Ronald PC (2013) Recent advances in dissecting stress-regulatory crosstalk in rice. Mol Plant: DOI: $10.1093 / \mathrm{mp} / \mathrm{sss} 1147$. 